\title{
The impact of African-trained neurosurgeons on sub-Saharan Africa
}

\author{
Claire Karekezi, MD, ${ }^{1}$ Abdeslam El Khamlichi, MD, PhD, ${ }^{2}$ Abdessamad El Ouahabi, MD, ${ }^{3}$ \\ Najia El Abbadi, MD, ${ }^{4}$ Semevo Alidegnon Ahokpossi, MD, ${ }^{5}$ Kodjo Mensah Hobli Ahanogbe, MD, ${ }^{6}$ \\ Ibrahima Berete, MD, ${ }^{7}$ Soueilem Mohamed Bouya, MD, ${ }^{8}$ Oumar Coulibaly, MD, ${ }^{9}$ Ibrahim Dao, MD, ${ }^{10}$ \\ Ben Ousmanou Djoubairou, MD, ${ }^{11}$ Agbeko Achille Komlan Doleagbenou, MD, ${ }^{6}$ \\ Komi Prosper Egu, MD, ${ }^{12}$ Hugues Brieux Ekouele Mbaki, MD,13 \\ Sinclair Brice Kinata-Bambino, MD, ${ }^{13}$ Laminou Mahamane Habibou, MD, ${ }^{14}$ \\ Adio Nabil Mousse, MD, ${ }^{15}$ Trésor Ngamasata, MD, ${ }^{16}$ Jeff Ntalaja, MD, ${ }^{17}$ Justin Onen, MD,,${ }^{18}$ \\ Kisito Quenum, MD, ${ }^{19}$ Diawara Seylan, MD, ${ }^{7}$ Youssouf Sogoba, MD, ${ }^{20}$ Franco Servadei, MD, ${ }^{21}$ and \\ Isabelle M. Germano, MD, MBA ${ }^{22}$
}

\begin{abstract}
'Department of Neurosurgery, Rwanda Military Hospital, Kigali, Rwanda; ${ }^{2}$ National Center for Rehabilitation and Neurosciences, Hôpital des Spécialités de Rabat; ${ }^{3}$ Department of Neurosurgery, Hôpital des Spécialités ONO, Rabat Medical School; ${ }^{4}$ Department of Neurosurgery, Cheikh Zaid International Hospital, Abulcasis International University of Health Sciences, Rabat, Morocco; ${ }^{5}$ Neurosurgery Department, Hôpital Bethesda, Cotonou, Benin Republic; ${ }^{6}$ Neurosurgery Department, CHU Sylvanus Olympio, University of Lome, Republic of Togo; ${ }^{7}$ Department of Neurosurgery, Medical School at University Gamal Abdel Nasser of Conakry, Guinea; ${ }^{8}$ Department of Neurosurgery, Military Hospital of Nouakchott, Mauritania; ${ }^{9}$ Department of Neurosurgery, Hôpital du Mali, Bamako, Mali; ${ }^{10}$ Department of Neurosurgery, University Hospital Yalgafo Ouedraogo and Military Camp General Sangoule Lamizana, University Nazi Boni, Bobo-Dioulasso, Burkina Faso; ${ }^{11}$ Department of Neurosurgery, Military Hospital of Yaoundé, Cameroon; ${ }^{12}$ Polyclinique Saint Joseph, Lome, Republic of Togo; ${ }^{13}$ Division of Neurosurgery, University Hospital Center of Brazzaville, Marien Ngouabi University, Brazzaville, Republic of Congo; ${ }^{14}$ General Reference Hospital of Niamey, Niger; ${ }^{15} \mathrm{Clinique}$ Mahouena, Cotonou, Benin Republic; ${ }^{16} \mathrm{Hopital}$ General Provincial de Kinshasa; ${ }^{17} \mathrm{Hopital}$ Ngaliema, Kinshasa, Democratic Republic of Congo; ${ }^{18}$ CURE Children's Hospital of Uganda, Mbale, Uganda; ${ }^{19}$ Neurosurgery Department of Parakou University, Parakou, Benin Republic; ${ }^{20}$ Gabriel Toure Teaching Hospital, Bamako, Mali; ${ }^{21}$ Department of Neurosurgery, Humanitas Clinical and Research Hospital and Humanitas University, Milan, Italy; and ${ }^{22}$ Department of Neurosurgery, Icahn School of Medicine at Mount Sinai, Mount Sinai Health System, New York, New York
\end{abstract}

OBJECTIVE Sub-Saharan Africa (SSA) represents $17 \%$ of the world's land, $14 \%$ of the population, and $1 \%$ of the gross domestic product. Previous reports have indicated that 81/500 African neurosurgeons (16.2\%) worked in SSA-i.e., 1 neurosurgeon per 6 million inhabitants. Over the past decades, efforts have been made to improve neurosurgery availability in SSA. In this study, the authors provide an update by means of the polling of neurosurgeons who trained in North Africa and went back to practice in SSA.

METHODS Neurosurgeons who had full training at the World Federation of Neurosurgical Societies (WFNS) Rabat Training Center (RTC) over the past 16 years were polled with an 18-question survey focused on demographics, practice/case types, and operating room equipment availability.

RESULTS Data collected from all 21 (100\%) WFNS RTC graduates showed that all neurosurgeons returned to work to SSA in 12 different countries, 90\% working in low-income and 10\% in lower-middle-income countries, defined by the World Bank as a Gross National Income per capita of $\leq$ US\$995 and US\$996-\$3895, respectively. The cumulative population in the geographical areas in which they practice is 267 million, with a total of 102 neurosurgeons reported, resulting in 1 neurosurgeon per 2.62 million inhabitants. Upon return to SSA, WFNS RTC graduates were employed in public/private hospitals (62\%), military hospitals (14.3\%), academic centers $(14.3 \%)$, and private practice $(9.5 \%)$. The majority reported an even split between spine and cranial and between trauma and elective; $71 \%$ performed between 50 and more than 100 neurosurgical procedures/year. Equipment available varied across the cohort. A CT scanner was

ABBREVIATIONS CME = continuing medical education; DRC = Democratic Republic of Congo; GNI = Gross National Income; LMIC = low- and middle-income countries; RTC = Rabat Training Center; SSA = sub-Saharan Africa; WFNS = World Federation of Neurosurgical Societies.

SUBMITTED November 2, 2019. ACCEPTED December 19, 2019.

INCLUDE WHEN CITING DOI: 10.3171/2019.12.FOCUS19853. 
available to $86 \%$, MRI to $38 \%$, surgical microscope to $33 \%$, endoscope to $19.1 \%$, and neuronavigation to $0 \%$. Three $(14.3 \%)$ neurosurgeons had access to none of the above.

CONCLUSIONS Neurosurgery availability in SSA has significantly improved over the past decade thanks to the dedication of senior African neurosurgeons, organizations, and volunteers who believed in forming the new neurosurgery generation in the same continent where they practice. Challenges include limited resources and the need to continue expanding efforts in local neurosurgery training and continuing medical education. Focus on affordable and low-maintenance technology is needed.

https://thejns.org/doi/abs/10.3171/2019.12.FOCUS19853

KEYWORDS sub-Saharan Africa; neurosurgery training; global neurosurgery; low- and middle-income countries; LMIC

$\mathrm{A}$ CCORDING to current data, there are an estimated 49,940 neurosurgeons in the world with a great disparity in ratio among countries, ranging from 0 to 59 per 1 million people. ${ }^{11}$ Sub-Saharan Africa (SSA) represents $17 \%$ of the world's land, $14 \%$ of the world's population, and $1 \%$ of the world's gross domestic product. $^{22,25}$ Reports from the beginning of the 21st century indicated that only $81(16.2 \%)$ of the 500 African neurosurgeons worked in SSA, with a neurosurgeon ratio of approximately 1 per 6 million people. ${ }^{4-7}$ This limitation in workforce was highlighted as one of the major barriers to neurosurgical care. .,3 $^{2,}$

To address this issue, efforts were made to improve neurosurgery training in SSA. Among these efforts, the World Federation of Neurosurgical Societies (WFNS) Rabat Training Center (RTC) was established in 2002 after an agreement between the Mohammed V University, the Faculty of Medicine and Pharmacy of Rabat, and the WFNS Foundation. ${ }^{4}$ Over the past 16 years, this center allowed for full or partial training of many African neurosurgeons. ${ }^{7,8}$ Through this passion for training engendered by the WFNS initiative, the number of neurosurgeons in SSA increased 5-fold over the past 18 years, from 79 in 1998 to 369 in 2016.6

To follow up on the local integration and the challenges the WFNS RTC African neurosurgeons face after their return to SSA, we surveyed all fully trained neurosurgeons. In this study, we provide the data relative to this cohort.

\section{Methods \\ Neurosurgeon Cohort}

Over the past 16 years, neurosurgery residents from 18 countries in SSA joined the WFNS RTC. ${ }^{6}$ Twentytwo neurosurgery residents had a formal 5 years of full training; among these was RTC's first trainee, Dr. Mudjir Didier Balanda from the Democratic Republic of Congo (DRC) who passed away in 2012. An additional 7 residents include 6 trainees from Nigeria and 1 from Tanzania who had a combined training and graduated from the home universities and regional surgical colleges. This methodology explains differences with previously reported information. ${ }^{8}$

\section{Survey Specifics}

Using an online SurveyMonkey poll, we administered a voluntary neurosurgery-specific survey to the last 21 con- secutive neurosurgeons who had received formal training from the WFNS RTC.

Key outcome measures included demographic information, country neurosurgical workforce, access to imaging modalities and instruments, volume, and breakdown of neurosurgical cases. The survey remained open for 30 days starting from October 29, 2018. Three neurosurgeons who could not access it online were surveyed interactively by phone with the same questions. The number of neurosurgeons in each country was provided by the neurosurgeons who participated in the survey with data pertinent to October 2018. In case of information discrepant from previously published data or between 2 neurosurgeons from the same country, the survey responders were contacted (C.K., I.M.G.) and asked to provide additional documentation until such discrepancy was resolved.

\section{Statistical Analysis}

Descriptive statistics are reported either as the total number of events with valid percentage or as an average. An unpaired Student t-test was used to analyze the data. A p value $<0.05$ was considered significant. Data were analyzed using commercially available Microsoft Excel software.

\section{Results}

\section{Demographic Data}

Table 1 summarizes the cohort's and countries' characteristics. All (100\%) fully trained neurosurgery residents who graduated from the WFNS RTC replied to the survey $(\mathrm{N}=21)$. Twenty of 21 surveys had complete responses $(95.2 \%)$. All neurosurgeons surveyed $(100 \%)$ returned to work in 12 different SSA countries: Benin, Burkina Faso, Cameroon, Republic of Congo, DRC, Guinea Conakry, Mali, Mauritania, Niger, Rwanda, Togo, and Uganda. The age range was $30-59$ years, with $52 \%$ of the respondents between 30 and 39 years. Sex was predominantly male, with $2 / 21$ women $(9.5 \%)$. Trainees were predominantly from francophone countries $(90.5 \%)$. The reported number of neurosurgeons per country listed by the respondents is shown in Table 1.

Upon completion of training, $90 \%$ of graduates work in low-income and $10 \%$ in lower-middle-income countries, defined by the World Bank (2019) as a Gross National Income (GNI) per capita of $\leq$ US\$995 and US\$996-\$3895, respectively ${ }^{20}$ The cumulative population in the geograph- 
TABLE 1. Characteristics of WFNS RTC neurosurgery graduates and countries

\begin{tabular}{|c|c|c|c|c|c|c|c|}
\hline Country & $\begin{array}{c}\text { No. of WFNS RTC } \\
\text { Graduates }\end{array}$ & $\begin{array}{l}\text { Total No. of } \\
\text { NS Surveyed }\end{array}$ & Sex & $\begin{array}{c}\text { Country's Total No. } \\
\text { of NS }\end{array}$ & Population (M)* & Area $\left(\mathrm{mi}^{2}\right) \dagger$ & $\begin{array}{c}\text { Country's NS/Inhabitant } \\
\text { Ratio }\end{array}$ \\
\hline Benin & 3 & 3 & M & 10 & 11.485 & 44.310 & 1:1.118 \\
\hline Burkina Faso & 1 & 1 & M & 5 & 19.751 & 105.869 & 1:9.595 \\
\hline Cameroon & 1 & 1 & M & 16 & 25.216 & 183.569 & $1: 1.576$ \\
\hline Republic of Congo & 2 & 2 & $M$ & 5 & 5.245 & 132.047 & $1: 1.052$ \\
\hline DRC & 2 & 2 & M & 7 & 84.069 & 905.400 & 1:11.61 \\
\hline Guinea Conakry & 2 & 2 & $\mathrm{M}, \mathrm{F}$ & 5 & 12.72 & 94.926 & $1: 2.544$ \\
\hline Mali & 3 & 3 & M & 13 & 19.077 & 478.800 & 1:1.467 \\
\hline Mauritania & 1 & 1 & $M$ & 10 & 4.403 & 397.700 & 1:0.44 \\
\hline Niger & 1 & 1 & M & 8 & 22.442 & 489.700 & $1: 2.685$ \\
\hline Rwanda & 1 & 1 & $\mathrm{~F}$ & 6 & 12.301 & 10.169 & $1: 2.035$ \\
\hline Togo & 3 & 3 & M & 6 & 7.890 & 21.925 & 1:1.3 \\
\hline Uganda & 1 & 1 & $M$ & 11 & 42.723 & 93.065 & 1:3.896 \\
\hline Total & 21 & 21 & $19 \mathrm{M}, 2 \mathrm{~F}$ & 102 & 267.322 & 2957.480 & $1: 2.620$ \\
\hline
\end{tabular}

NS = neurosurgeons.

* Per 2018 https://data.worldbank.org/countryl (World Bank, ref. 25).

† Per https://www.google.com/ and World Bank, ref. 25.

ical areas in which they practice is 267 million, with a total of 102 neurosurgeons reported, resulting in 1 neurosurgeon per 2.62 million inhabitants.

\section{Employment, Neurosurgical Caseload, and Available Resources}

Table 2 summarizes the cohort's professional experience. Upon return to SSA, WFNS RTC graduates were employed in public/private hospitals (62\%), military hospitals $(14.3 \%)$, academic centers $(14.3 \%)$, and private practice $(9.5 \%)$. There was no statistical difference between their completion of residency and years in practice, signifying a prompt employment upon return.

Neurosurgical caseload showed that $71 \%$ of neurosurgeons performed between 50 and more than 100 neurosurgical procedures per year, with the majority reporting an even split between spine and cranial and between trauma and elective (Fig. 1).

Equipment available varied across the cohort (Table 3). A CT scanner was available to $86 \%$ of neurosurgeons and MRI to $38 \%$. Only $33 \%$ of the surveyed neurosurgeons had access to a surgical microscope, and only 4 (19.1\%) had an endoscope. Neuronavigation was not available to any neurosurgeons (0\%). Additionally, 3 (14.3\%) neurosurgeons had access to none of the above.

\section{Discussion}

Africa as a continent has been facing heavy challenges in terms of healthcare over the last decades. Surgery in general has been left behind for many years, and neurosurgery has particularly been overlooked and falsely considered as expensive and luxury care. ${ }^{3,4,11,18}$ In 2015 , the Lancet Commission on Global Surgery estimated that 143 million additional surgical procedures are needed in lowand middle-income countries (LMIC) each year, ${ }^{10,19}$ and further studies revealed that approximately $15 \%$ of those surgical procedures are neurosurgical..$^{13,15,16}$ Neurosurgical conditions affect people worldwide, regardless of age, sex, income, or level of education. These conditions include traumatic brain injuries, degenerative diseases, and congenital disorders, which seem to affect even more people in low-income settings and in Africa. These diseases altogether cause more than 6.8 million deaths per year, the same number as that of deaths caused by AIDS, tuberculosis, and malaria. ${ }^{11,18}$ Numbers show that an estimated 5 million essential neurosurgical cases go untreated in LMIC each year and that more than 23,000 more neurosurgeons are needed in these countries by 2030 to address this issue. ${ }^{1,3,13}$

Neurosurgery arrived in Africa a bit later than in Europe and North America, especially in the sub-Saharan

\section{TABLE 2. Professional work experience}

\begin{tabular}{ccr}
\hline Professional Experience \& Workplace & No. of NS (N = 21) & $\%$ \\
\hline Employment type & & \\
\hline Public hospital & 7 & $33.3 \%$ \\
\hline Public \& private & 6 & $28.6 \%$ \\
\hline Private practice & 2 & $9.5 \%$ \\
\hline Military hospital & 3 & $14.3 \%$ \\
\hline Academic institution & 3 & $14.3 \%$ \\
\hline Yrs since residency & & \\
\hline 1 to $<5$ & 16 & $76.2 \%$ \\
\hline$\geq 5$ to $<10$ & 3 & $14.3 \%$ \\
\hline$\geq 10$ & 2 & $9.5 \%$ \\
\hline Yrs in practice & & \\
\hline 1 to $<5$ & 15 & $71.4 \%$ \\
\hline$\geq 5$ to $<10$ & 4 & $19.1 \%$ \\
\hline$\geq 10$ & 2 & $9.5 \%$ \\
\hline
\end{tabular}


A
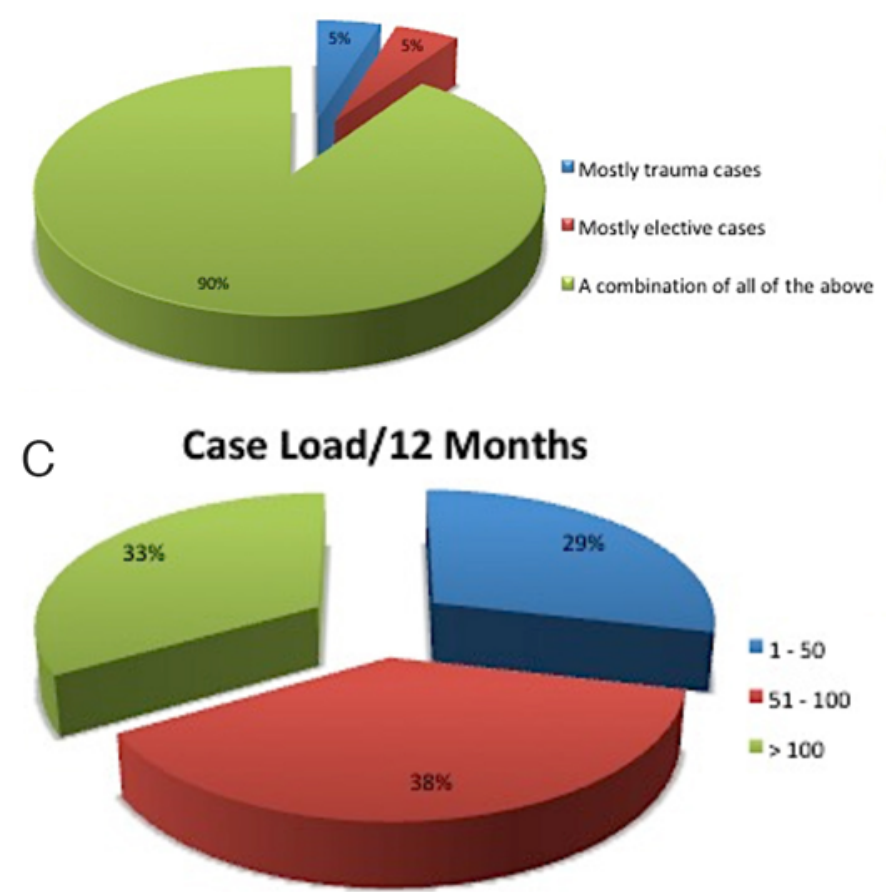

B Cranial Vs Spine Cases
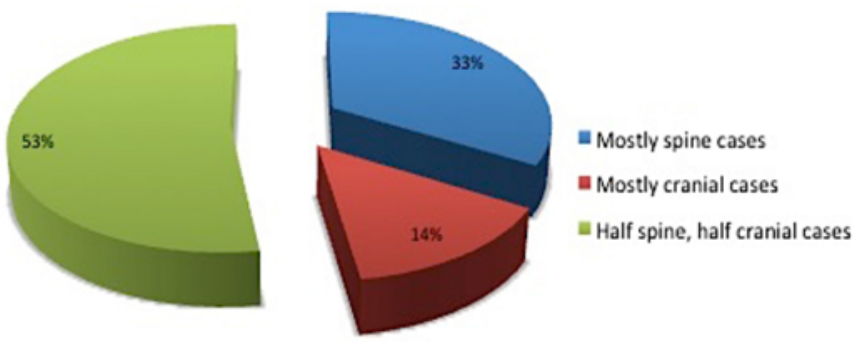

FIG. 1. Pie charts summarizing the types of neurosurgical cases. A: Elective versus trauma. B: Cranial versus spine. C: Summary of yearly caseload.

region; neurosurgical training came even later. ${ }^{4-6}$ This delay is a combination of many factors. These include the historical colonial context of Africa and the choice of the majority of African countries, after their independence, to train their young doctors-including neurosurgeons-outside of Africa (in Europe and North America), which resulted in significant brain drain during the second half of the 20th century. ${ }^{6}$ In addition, the paucity of existing neurosurgeons, the failure to integrate neurosurgical training into existing surgical curricula due to limited equipment and supplies to support diagnostic imaging capabilities, and an inadequate surgical infrastructure restricting the few available neurosurgeons in providing adequate care, along with the limited financial ability of patients.

Our study shows that only approximately one-third of neurosurgeons surveyed perform more than 100 cases per year. Although our survey was not powered to explore the causes of this fact, it is plausible to suggest that these well-trained neurosurgeons cannot be used to their full potential without the infrastructure needed to increase their reach. Another important factor is the reality that in countries with low income, patients with neurosurgical conditions do not have the means to care for themselves, and they present at very late stages - making the treatment difficult and increasing morbidity and mortality. ${ }^{1-5}$

Previous publications on African neurosurgery have shown inequality in terms of neurosurgeon distribution in the African continent, with most of the practitioners being located in North Africa. ${ }^{4}$ Reports from the beginning of the 21st century indicated that only $81(16.2 \%)$ of all 500 African neurosurgeons worked in SSA with a rate of approximately 1 neurosurgeon per 6 million inhabitants, and that approximately $70.8 \%$ were in North Africa. ${ }^{4-6,8}$ The realities of such a misdistribution made the training in neurosurgery even more difficult. Training did not exist in many countries until the late 1990s. Most senior African neurosurgeons trained abroad, and some were able to establish neurosurgical training in their home countries. Our study shows a considerable improvement in alignment with more recent reports. ${ }^{6,20}$ Using 2018 population data we report 102 fully trained neurosurgeons working in 12 SSA countries, corresponding to a ratio of 1 neurosurgeon per 2.62 million people. ${ }^{22}$ The difference in the ratio of neurosurgeons/population compared to published reports ${ }^{7,8,20}$ can be explained by different facts. First, our study is pertinent to only 12 of the 46 United Nations-defined SSA countries, namely the 12 where the WFNS RTC graduates practice. Second, our study was conducted in 2018 and the 2018 population data were used as published by the World Bank. ${ }^{25}$ Third, the number of neurosurgeons in each country is self-reported by each neurosurgeon or group of neurosurgeons residing in that country.

\section{Neurosurgical Education and Training in SSA}

Providing a comprehensive and effective neurosurgical service requires adequate numbers of well-trained, wellresourced, and well-motivated neurosurgeons, but many factors still make this practice difficult in SSA: geographic isolation of many communities, bureaucratic resistance, political instability, constant socioeconomic changes, and high rates of poverty and illiteracy in rapidly growing populations. ${ }^{2,15,16,18}$ Many efforts have been made to improve neurosurgery training in SSA over the last 2 decades. ${ }^{6}$ Our 
TABLE 3. Available operating room equipment

\begin{tabular}{lcc}
\hline Type of Equipment & No. of NS w/ Access (N = 21) & $\%$ \\
\hline CT scanner & 18 & $85.7 \%$ \\
\hline MRI & 8 & $38 \%$ \\
\hline Microscope & 7 & $33.3 \%$ \\
\hline Endoscope & 4 & $19.1 \%$ \\
\hline Neuronavigation & 0 & $0 \%$ \\
\hline Ultrasound & 2 & $9.5 \%$ \\
\hline None & 3 & $14.3 \%$ \\
\hline
\end{tabular}

paper shows that the vision of the WFNS RTC to train neurosurgeons in the same continent in which they would practice was very successful, with $100 \%$ of the trainees retained within the African continent and $90 \%$ of them working in low-income countries in SSA.

The success of the WFNS RTC, the permanent support of the WFNS, and the engagement of senior African neurosurgeons led to the creation of other WFNS Regional Training Centers in Africa (Algeria, Kenya, and Senegal). ${ }^{6-8}$ At the same time, the number of African countries involved in a national neurosurgery training program moved from 5 in 1998 to 21 in 2018; among them 16 in SSA countries. Some of these training programs in SSA countries are still integrated with surgical education. Many other organizations-private and/or with government/university support-have also contributed to neurosurgeon training in Africa, including the Africa 100 Project. ${ }^{6,17}$ Hopefully, all of these concerted efforts will continue to result in an increased number of trained African neurosurgeons.

\section{Resource Availability}

Neurosurgical practice highly depends on the availability of surgical equipment, especially in LMIC where resources are limited. The WFNS Foundation has been providing basic instruments to young neurosurgeons starting their career, with a positive influence on their neurosurgical practice. Our study shows that only 1 in 3 neurosurgeons has access to a surgical microscope. This clearly is a limiting factor to the types of neurosurgical procedures that can be performed and poses questions about safety. Imaging modalities like CT and MRI are also essential tools in neurosurgery. These are not luxury items; they are needed to provide basic care in emergency settings for diagnosis of all neurotrauma cases, infections, and acute stroke. Multiple studies have shown that the advent of CT imaging reduces mortality in the setting of trauma and infections, which are more frequent in lower-income settings. 9,12,14,23 Lack of timely imaging leads to delay in surgical management and poor patient outcomes. ${ }^{18,23}$ Creating awareness of such need and involving all stakeholders, including the local governments, is essential to ensure sustainability and durability of instrument provision. ${ }^{24}$

\section{Future Directions and Opportunities}

The components of each well-functioning health system include access to essential medical care, adequate healthcare delivery by means of sufficient workforce, and health information resources. These components are the same for neurosurgical care delivery. Thanks to the great efforts of the WFNS and many other organizations the workforce in SSA has been substantially increased. A strategy to increase the training capacity in all existing training centers in Africa (21 centers), with the goal to raise the current number of neurosurgeons in SSA to 369 has recently been proposed. ${ }^{6}$ In addition to increasing the neurosurgical workforce, there is still a lot of work to be accomplished, including creating an adequate infrastructure allowing African-trained neurosurgeons to function and progress as neurosurgeons. The existing barriers within the health systems must be addressed in order to allow a trained neurosurgeon to fulfill his/her responsibilities. There is also a need for developing other supportive specialties like neuroradiology, neuro-intensive care, neuro-anesthesia, neuropathology, and nursing-on which neurosurgery practice tightly depends. Recognizing these needs that must be addressed is an important step to implement efficient and quality neurosurgery delivery systems in LMIC. $1,2,18$

Our study shows that $90 \%$ of WFNS RTC graduates work in countries with a GNI per capita of $\leq$ US\$995. It is therefore clear that affordable continuing medical education (CME) should be a goal for the next decade. It is very unlikely that such neurosurgeons can travel abroad to participate in international meetings in which the registration fee might be the equivalent of $50 \%$ of the annual GNI. A concerted effort of world organizations to work at providing such training could be beneficial to all parties. On the other hand, it is time to develop and expand an African CME program based on local pathology and working environment. The WFNS-RTC course for young African neurosurgeons, ${ }^{6,7}$ organized every year since 2007 , should be duplicated by other African neurosurgical societies in collaboration with the WFNS and other international institutions.

The lack of availability of neurosurgical equipment can be an opportunity for industry to collaborate with local governments. Following the Lancet Commission Report, in 2015 the World Health Assembly 68 passed the A68.15 resolution ${ }^{26}$ titled Strengthening Emergency and Essential Surgical Care and Anaesthesia as a Component of Universal Health Coverage. This proposition advocates for inclusion of surgical care in long-term governmental planning, and asserts that the problem is not solvable as a separate issue from social conditions or general healthcare planning. Moreover, surgical care is directly part of the 17 sustainable development goals action plan adopted by the United Nations in 2015. ${ }^{21}$ In 2018, during the 72nd World Health Assembly, a further resolution was passed, called Emergency Care Systems for Universal Health Coverage: Ensuring Timely Care for the Acutely Ill and Injured, addressing the staggering proportion of avoidable traumatic and surgical deaths. ${ }^{27}$ As local governments are addressing these resolutions, the involvement of physicians and the medical industry will be essential to move healthcare to the next step.

\section{Conclusions}

Neurosurgery availability in SSA has significantly improved over the past 2 decades thanks to the dedication of 
senior African neurosurgeons, organizations, and volunteers who believed in forming the new neurosurgery generation in the same continent where they practice. Challenges and opportunities include limited resources and the need to continue expanding efforts in local neurosurgery training to reach the 2030 strategy goal as well as CME offerings to allow progression of these well-trained neurosurgeons. A focus on affordable and low-maintenance technology is needed. Concerted educational efforts over the next decade should focus on further establishing neurosurgical subspecialty care.

\section{References}

1. Corley J, Lepard J, Barthelemy E, Ashby JL, Park KB. Essential neurosurgical workforce needed to address neurotrauma in low- and middle-income countries. World Neurosurgery 123:295-299, 2019

2. Dempsey KE, Qureshi MM, Ondoma SM, Dempsey RJ: Effect of geopolitical forces on neurosurgical training in SubSaharan africa. World Neurosurg 101:196-202, 2017

3. Dewan MC, Rattani A, Fieggen G, Arraez MA, Servadei F, Boop FA, et al: Global neurosurgery: the current capacity and deficit in the provision of essential neurosurgical care. J Neurosurg 130:1039-1408, 2019

4. El Khamlichi A: African neurosurgery: current situation, priorities, and needs. Neurosurgery 48:1344-1347, 2001

5. El Khamlichi A: African neurosurgery part II: current state and future prospects. Surg Neurol 49:342-347, 1998

6. El Khamlichi A: Emerging Neurosurgery in Africa, presented at 6th MASSIN Congress, Becici, Budva, Montenegro, October 26-29, 2019

7. El Khamlichi A: The World Federation of Neurosurgical Societies Rabat Reference Center for Training African Neurosurgeons: an experience worthy of duplication. World Neurosurg 81:234-239, 2014

8. Karekezi C, El Khamlichi A: Takeoff of African Neurosurgery and the World Federation of Neurosurgical Societies Rabat Training Center Alumni. World Neurosurg 126:576580, 2019

9. Maas AIR, Steyerberg EW, Butcher I, Dammers R, Lu J, Marmarou A, et al: Prognostic value of computerized tomography scan characteristics in traumatic brain injury: results from the IMPACT study. J Neurotrauma 24:303-314, 2007

10. Meara JG, Leather AJM, Hagander L, Alkire BC, Alonso N, Ameh EA, et al: Global Surgery 2030: evidence and solutions for achieving health, welfare, and economic development. Lancet 386:569-624, 2015

11. Mukhopadhyay S, Punchak M, Rattani A, Hung YC, Dahm J, Faruque S, et al: The global neurosurgical workforce: a mixed-methods assessment of density and growth. J Neurosurg 130:1142-1148, 2019

12. Nelson DW, Nyström H, MacCallum RM, Thornquist B, Lilja A, Bellander BM, et al: Extended analysis of early computed tomography scans of traumatic brain injured patients and relations to outcome. J Neurotrauma 27:51-64, 2010

13. Park KB, Johnson WD, Dempsey RJ: Global neurosurgery: the unmet need. World Neurosurg 88:32-35, 2016

14. Robertson FC, Lepard JR, Mekary RA, Davis MC, Yunusa I, Gormley WB, et al: Epidemiology of central nervous system infectious diseases: a meta-analysis and systematic review with implications for neurosurgeons worldwide. J Neurosurg 130:1107-1126, 2019

15. Sader E, Yee P, Hodaie M: Assessing barriers to neurosurgical care in Sub-Saharan africa: the role of resources and infrastructure. World Neurosurg 98:682-688.e3, 2017

16. Sader E, Yee P, Hodaie M: Barriers to neurosurgical training in Sub-Saharan Africa: the need for a phased approach to global surgery efforts to improve neurosurgical care. World Neurosurg 98:397-402, 2017

17. Samii M: Introducing the Africa 100 Project-Speech at the CAANS. Hannover, Germany: World Federation of Neurosurgical Societies, 2016 (https://www.youtube.com/ watch?v=nW9bwF3RK2I) [Accessed January 10, 2020]

18. Servadei F, Rossini Z, Nicolosi F, Morselli C, Park KB: The role of neurosurgery in countries with limited facilities: facts and challenges. World Neurosurg 112:315-321, 2018

19. Shrime MG, Bickler SW, Alkire BC, Mock C: Global burden of surgical disease: an estimation from the provider perspective. Lancet Glob Health 3 (Suppl 2):S8-S9, 2015

20. Tropeano MP, Spaggiari R, Ileyassoff H, Park KB, Kolias AG, Hutchinson PJ, et al: A comparison of publication of TBI ratio of low- and middle-income countries versus highincome countries: how can we improve worldwide care of TBI? Neurosurg Focus 47(5):E5, 2019

21. United Nations: Transforming Our World: The 2030 Agenda for Sustainable Development. New York: United Nations (https://sustainabledevelopment.un.org/post2015/ transformingourworld) [Accessed January 10, 2020]

22. United Nations Department of Economic and Social Affairs: World Population Prospects: 2019. New York: United Nations (https://population.un.org/wpp/DataQuery/) [Accessed January 10, 2020]

23. Upadhyayula PS, Yue JK, Yang J, Birk HS, Ciacci JD: The current state of rural neurosurgical practice: an international perspective. J Neurosci Rural Pract 9:123-131, 2018

24. Venturini S, Park KB: Evaluating the effectiveness and the impact of donated neurosurgical equipment on neurosurgical units in low- and middle-income countries: the World Federation of Neurosurgical Societies experience. World Neurosurg 109:98-109, 2018

25. World Bank: Open Data Country. Washington, DC: World Bank (https://data.worldbank.org/country) [Accessed January 10, 2020]

26. World Health Assembly: Strengthening Emergency and Essential Surgical Care and Anaesthesia as a Component of Universal Health Coverage. WHA68.15. Geneva: WHO (http://apps.who.int/gb/ebwha/pdf_files/WHA68/A68_R15en.pdf) [Accessed January 10, 2020]

27. World Health Organization: Emergency Care Systems for Universal Health Coverage: Ensuring Timely Care for the Acutely IIl and Injured. Geneva: WHO (http://apps.who. int/gb/ebwha/pdf_files/WHA72/A72_77-en.pdf) [Accessed January 10, 2020]

\section{Disclosures}

Dr. Germano: Brainlab and Integra (consultant), and Elminda (stock owner); neither is in direct conflict with this study. Dr. Servadei: Finceramica and Integra (consultant).

\section{Author Contributions}

Conception and design: Karekezi, Germano. Acquisition of data: Karekezi, Germano. Analysis and interpretation of data: Karekezi, Germano. Drafting the article: Karekezi, Germano. Critically revising the article: Karekezi, El Khamlichi, Servadei, Germano. Reviewed submitted version of manuscript: Karekezi, El Ouahabi, El Abbadi, Ahokpossi, Ahanogbe, Berete, Bouya, Coulibaly, Dao, Djoubairou, Doleagbenou, Egu, Ekouele Mbaki, Kinata-Bambino, Habibou, Mousse, Ngamasata, Ntalaja, Onen, Quenum, Seylan, Sogoba, Servadei, Germano. Approved the final version of the manuscript on behalf of all authors: Karekezi. Study supervision: Germano.

\section{Correspondence}

Claire Karekezi: Rwanda Military Hospital, Kigali, Rwanda. clairekarekezi@gmail.com. 